\title{
Rate corrected systolic time intervals and Valsalva manoeuvre
}

\author{
Clive Layton, Horacio di Nunzio, Graham Gent, Peter Freedman, and Alastair McDonald \\ From the Cardiac Department, The London Hospital, Whitechapel, London
}

Measurements of left ventricular systolic time intervals during the Valsalva manoeuvre have been made in Io normal subjects, 5 patients with ischaemic heart disease before and after treatment with a beta adrenergic blocking drug, and 5 patients with cardiomyopathy. The individual relation between the heart rate and the left ventricular ejection time was established in the normal subjects during the intravenous infusion of atropine sulphate. The regression equations obtained were used to eliminate the effects of the changing heart rate on the ejection time during the Valsalva manoeuvre. Following this correction a consistent pattern emerged related to the changes in stroke volume known to occur during the Valsalva manoeuvre.

In the presence of impaired myocardial function there was no significant fall in the left ventricular ejection time during the strain period. The overshoot, seen in normal subjects, in the corrected ejection time ratio after release of the strain is also lost. After beta adrenergic receptor blockade the post-release overshoot was blocked, and in addition there was an increase in the resting levels of the uncorrected ventricular ejection time which cannot be explained solely on the basis of the fall in heart rate observed after beta adrenergic blockade.

It is suggested that this noninvasive technique may provide a useful alternative to direct arterial pressure recording in the assessment of the cardiovascular and autonomic responses to the Valsalva manoeuvre.

The Valsalva manoeuvre is a well-established test by which the response of the cardiovascular and autonomic nervous systems to a stress may be studied (Elisberg et al., 1953; Gorlin, Knowles, and Storey, 1957). It has been customary to measure the responses in terms of a change in heart rate (Elisberg, 1963) and systemic arterial pressure (Sarnoff, Hardenbergh, and Whittenberger, 1948), the measurement of which by arterial puncture has limited the value of this method in the sequential study of cardiovascular and autonomic disorders.

Measurement of the duration of the phases of left ventricular systole using external carotid pulse tracings was described at the beginning of this century (Bowen, 1904), and increasing attention has recently been directed toward the significance of such measurements in the assessment of left ventricular function. Several observations have been made relating left ventricular systolic time intervals, and in particular the left ventricular ejection time (LVET), to normal and abnormal states of cardiac function. In the presence of cardiac failure a reduction in the LVET and an increase in the pre-ejection period (PEP) and PEP/LVET has been shown (Weissler, Received 16 August 1972.
Harris, and Schoenfeld, I968), but absolute levels are of limited value because of the large number of variable factors involved (Garrard, Weissler, and Dodge, 1970). Heart rate, stroke volume, and myocardial contractility have all been shown to affect systolic time intervals. The use of a stress test in conjunction with the measurement of left ventricular systolic time intervals has been suggested as a possible means of resolving these difficulties. Observations have been made after exercise (Pigott $e t$ al., I97I) and during the administration of digoxin and digitoxin (Shapiro, Narahara, and Taubert, 1970).

In order to establish the value of measurement of left ventricular systolic time intervals during the Valsalva manoeuvre, the response of the LVET, PEP, and PEP/LVET in a group of normal subjects during and after the Valsalva manoeuvre has been studied and the effects of changing heart rate on the systolic time intervals eliminated by comparing the results on a beat-by-beat basis with the previously determined normal value for that subject at the relevant heart rate during an atropine-induced sinus tachycardia.

Systolic time intervals during the Valsalva 
manoeuvre have also been measured in 5 patients with ischaemic heart disease before and after beta adrenergic receptor blockade with propranolol and in 5 patients with cardiomyopathy.

\section{Subjects and methods}

Ten healthy normal male volunteers (age range 25 to 33 years), and to patients with coronary arterial disease or cardiomyopathy, details of whom are shown in Table I, have been studied. Smoking was prohibited for 6 hours before the investigation which was performed in the postabsorptive state. All measurements were made with the subjects lying at an angle of 45 degrees. Simultaneous recordings of the electrocardiogram (lead II), phonocardiogram, and external carotid pulse waveform were obtained using a Cambridge multichannel photographic recorder at a nominal paper speed of $100 \mathrm{~mm} / \mathrm{sec}$. The phonocardiograms were recorded at medium frequency using piezoelectric crystal microphones placed at the left sternal edge in the second intercostal space and at the cardiac apex. The external carotid pulse waveform was obtained by a hand-held bell-shaped pickup using the air displacement technique. Great care was taken in positioning the bell to ensure that the onset of the rapid upstroke and the nadir of the dicrotic notch were sharp and that the quality of waveform was not impaired during the Valsalva manoeuvre.

Performance of the Valsalva manoeuvre was standardized by inflating a mercury sphygmomanometer column to a height of $40 \mathrm{~mm}$ and maintaining the strain for 15 seconds. A brief control period was recorded immedi-

\section{TABLE I Clinical details of patients studied}

\begin{tabular}{|c|c|c|c|}
\hline $\begin{array}{l}\text { Case } \\
\text { No. }\end{array}$ & Age/Sex & Diagnosis & Details \\
\hline $\mathbf{I}$ & $54 / M$ & $\begin{array}{l}\text { Ischaemic heart } \\
\text { disease }\end{array}$ & $\begin{array}{l}\text { Severe stenosis of right } \\
\text { coronary artery }\end{array}$ \\
\hline 2 & $50 / \mathrm{M}$ & $\begin{array}{l}\text { Ischaemic heart } \\
\text { disease }\end{array}$ & $\begin{array}{l}\text { Previous anterior car- } \\
\text { diac infarction }\end{array}$ \\
\hline 3 & $63 / M$ & $\begin{array}{l}\text { Ischaemic heart } \\
\text { disease }\end{array}$ & $\begin{array}{l}\text { Previous inferior car- } \\
\text { diac infarction }\end{array}$ \\
\hline 4 & $59 / \mathrm{M}$ & $\begin{array}{l}\text { Ischaemic heart } \\
\text { disease }\end{array}$ & $\begin{array}{l}\text { Previous anterior car- } \\
\text { diac infarction }\end{array}$ \\
\hline 5 & $44 / M$ & $\begin{array}{l}\text { Ischaemic heart } \\
\text { disease }\end{array}$ & $\begin{array}{l}\text { Stenosis of right } \\
\text { coronary artery }\end{array}$ \\
\hline 6 & $5 \mathrm{I} / \mathrm{M}$ & Cardiomyopathy & $\begin{array}{l}\text { Cardiomegaly; conges- } \\
\text { tive cardiac failure }\end{array}$ \\
\hline 7 & $62 / M$ & Cardiomyopathy & $\begin{array}{l}\text { Cardiomegaly; conges- } \\
\text { tive cardiac failure }\end{array}$ \\
\hline 8 & $32 / F$ & Cardiomyopathy & $\begin{array}{l}\text { Puerperal aetiology; } \\
\text { cardiomegaly; pul- } \\
\text { monary venous } \\
\text { congestion }\end{array}$ \\
\hline 9 & $60 / M$ & Cardiomyopathy & $\begin{array}{l}\text { Alcoholic aetiology; } \\
\text { cardiomegaly; left } \\
\text { ventricular failure }\end{array}$ \\
\hline 10 & $47 / M$ & Cardiomyopathy & $\begin{array}{l}\text { Alcoholic aetiology; } \\
\text { cardiomegaly; con- } \\
\text { gestive heart failure }\end{array}$ \\
\hline
\end{tabular}

ately before the strain, and after its release recording was continued for a further 20 to 30 seconds. Observations were repeated in the five patients with ischaemic heart disease after each had received $20 \mathrm{mg}$ propranolol every 8 hours by mouth for 48 hours.

In the normal subjects after performance of the Valsalva manoeuvre, a small cannula was introduced into a vein on the dorsum of the hand and an infusion of atropine sulphate was given at a rate of $0.2 \mathrm{mg}$ every 2 minutes until a heart rate of 120 beats a minute was achieved or a dose of $1.8 \mathrm{mg}$ had been administered. Recordings of 15 consecutive beats were made at 2minute intervals with the subject at rest, providing a total of approximately 130 beats at a variety of heart rates for each individual.

The left ventricular ejection time was obtained from the interval between the onset of the rapid upstroke of the carotid pulse and the nadir of the dicrotic notch (Fig. I). Total electromechanical systole (Q-S2) was measured as the period from the onset of the QRS complex of the electrocardiogram to the first high frequency component of the aortic second sound. The pre-ejection period was derived by subtracting the LVET from Q-S2. Errors due to transmission of the arterial pulse waveform to the transducer are therefore eliminated.

The recorder paper speed was found to vary by a factor of \pm 3 per cent when compared with an accurate 40 millisecond time marker derived from the 50 cycle/ second mains frequency. A correction was therefore

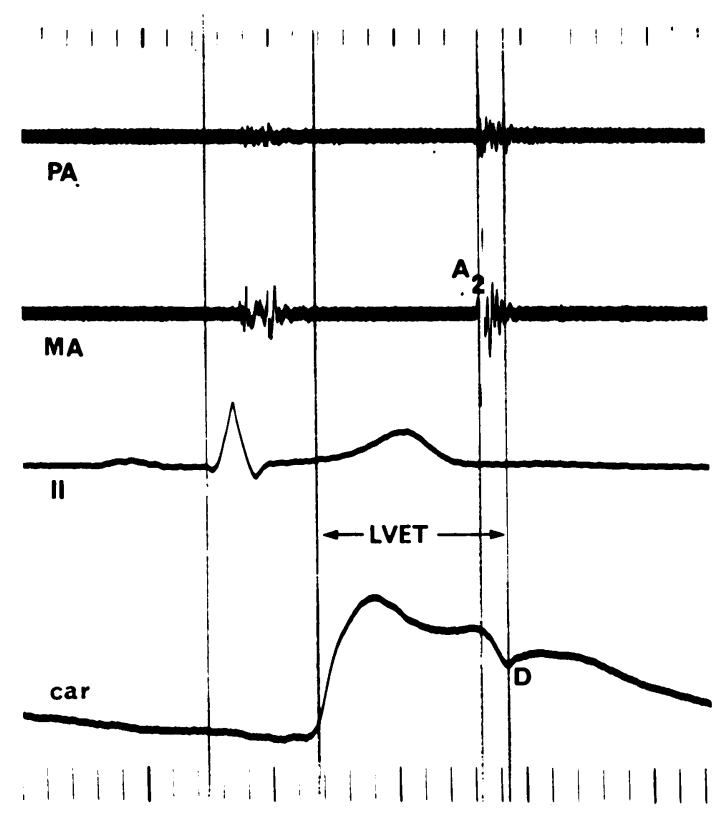

FIG. I Simultaneous phonocardiogram, electrocardiogram (lead II), and external carotid pulse waveform. $P A=$ pulmonary area; $M A=$ mitral area; $A_{2}=$ aortic component of the second heart sound; $D=$ dicrotic notch. 
applied to each trace using the time marker. With this technique it was possible to take measurements to the nearest 5 milliseconds.

The recordings for each subject were analysed on a beat-by-beat basis. The series obtained during atropine infusion was used to establish a relation between the heart rate and systolic intervals. A regression equation was calculated for each normal subject and the total data then pooled for calculation of a regression equation for the group. The changes in the LVET, PEP/LVET, and heart rate during the Valsalva manoeuvre were plotted. In order to exclude the effects of the heart rate on the LVET, a rate-corrected left ventricular ejection time ratio was calculated by subtracting the predicted LVET at the relevant heart rate $\left(\right.$ LVET $\left.^{\mathrm{p}}\right)$ from the observed measurement $\left(\mathrm{LVET}^{\circ}\right)$ and then expressing this difference as a percentage of the $L_{V E T}{ }^{p}$. The rate corrected LVET ratio may therefore be expressed as LVET $^{\circ}-$ LVET $^{\text {p }}$

\section{LVET $^{p}$}

heart rate was obtained from the individual regression equation for each normal subject and from the regression equation of the pooled data for the patients with ischaemic heart disease and cardiomyopathy.

\section{Results}

A linear relation was established between the heart rate and the LVET in each normal subject within the limits of rate achieved during the atropine infusion. The relation, which was highly significant $(\mathrm{P}<0.00 \mathrm{I})$, is expressed in the regression equations shown in Table 2 and the regression lines for individual and pooled data in Fig. 2 and 3.

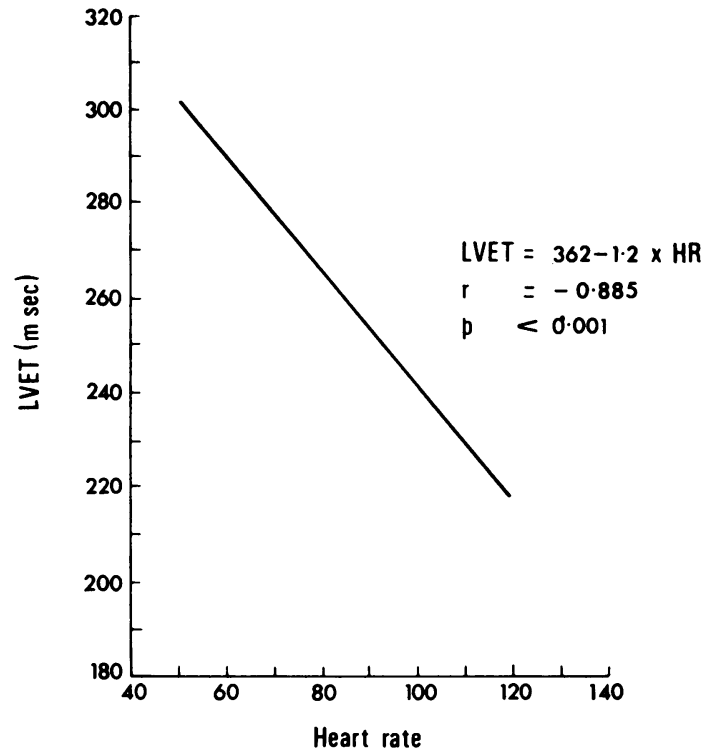

FIG. 3 Regression line derived from the pooled data during atropine infusion.

During the Valsalva manoeuvre similar responses were seen in each normal subject. The heart rate rose throughout phases II and III. In phase IV there was a sudden fall in rate followed by a gradual return to normal levels (Fig. 4). The LVET remained constant for the first four to six beats

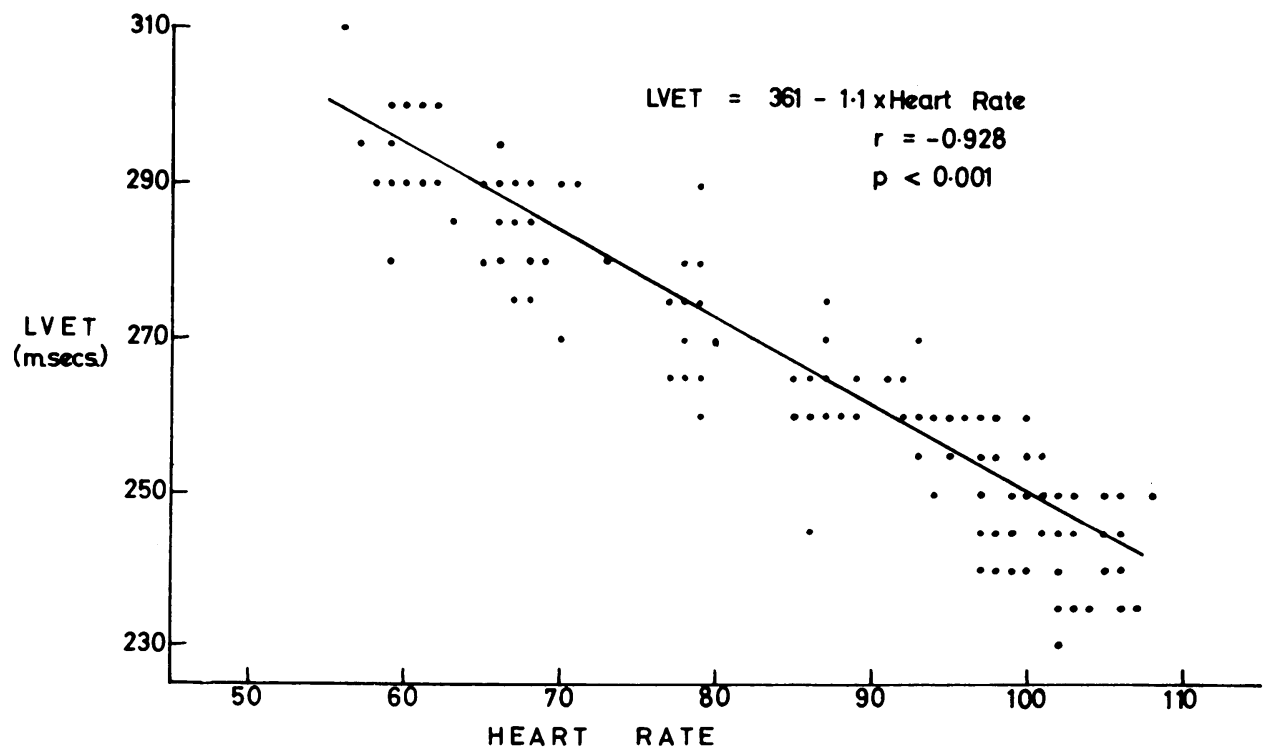

FIG. 2 Relation between LVET and heart rate (Case 2). Coincident points have been omitted for clarity. 
TABLE 2 Relation between LVET and heart rate during infusion of atropine sulphate

\begin{tabular}{cll}
\hline $\begin{array}{l}\text { Case } \\
\text { No. }\end{array}$ & $\begin{array}{l}\text { Regression equation } \\
(\text { LVET }=)\end{array}$ & $\begin{array}{l}\text { Coefficient of } \\
\text { correlation }\end{array}$ \\
\hline I & $332-\mathrm{I} \cdot 0 \times \mathrm{HR}$ & -0.757 \\
2 & $36 \mathrm{I}-\mathrm{I} \cdot \mathrm{I} \times \mathrm{HR}$ & -0.928 \\
3 & $358-\mathrm{I} \cdot 2 \times \mathrm{HR}$ & -0.964 \\
4 & $343-\mathrm{I} \cdot 0 \times \mathrm{HR}$ & -0.914 \\
5 & $406-\mathrm{I} \cdot 8 \times \mathrm{HR}$ & -0.966 \\
6 & $339-0.9 \times \mathrm{HR}$ & -0.907 \\
7 & $366-\mathrm{I} \cdot 2 \times \mathrm{HR}$ & -0.851 \\
8 & $324-\mathrm{I} \cdot 0 \times \mathrm{HR}$ & -0.964 \\
9 & $383-\mathrm{I} \cdot 5 \times \mathrm{HR}$ & -0.939 \\
IO & $336-0.7 \times \mathrm{HR}$ & -0.920 \\
\hline Total & $362-\mathrm{I} \cdot 2 \times \mathrm{HR}$ & -0.885 \\
\hline
\end{tabular}

after the start of the strain and then fell rapidly with a tendency to level off towards the end of phase II. This level was maintained for two to five beats after release of the strain and then returned rapidly to normal levels. The pre-ejection period re- mained unchanged throughout the Valsalva manoeuvre.

When the rate-corrected LVET ratio was plotted a clearer pattern emerged (Fig. 5). Immediately on starting phase I there was a rise in the LVET ratio reaching a peak within 5 beats. This was followed by a steady fall to a mean level of -25.6 per cent $(\mathrm{SD}=6.9 \%)$. This level was maintained into phase III and was then followed after release of the strain by a rapid rise, overshooting the control levels to a mean of $+14.8 \%(S D=6 \cdot 6 \%)$. A rapid return to the normal level follows but often with an obvious cyclical variation corresponding to the phases of respiration.

Since the PEP failed to alter during the Valsalva manoeuvre, the PEP/LVET showed an increase throughout phase II into phase III but with a plateau beginning to appear at the end of phase II (Fig. 6). After release of the strain there was a rapid return of the PEP/LVET to the control levels.

The initial studies performed in the 5 patients with ischaemic heart disease were within the range
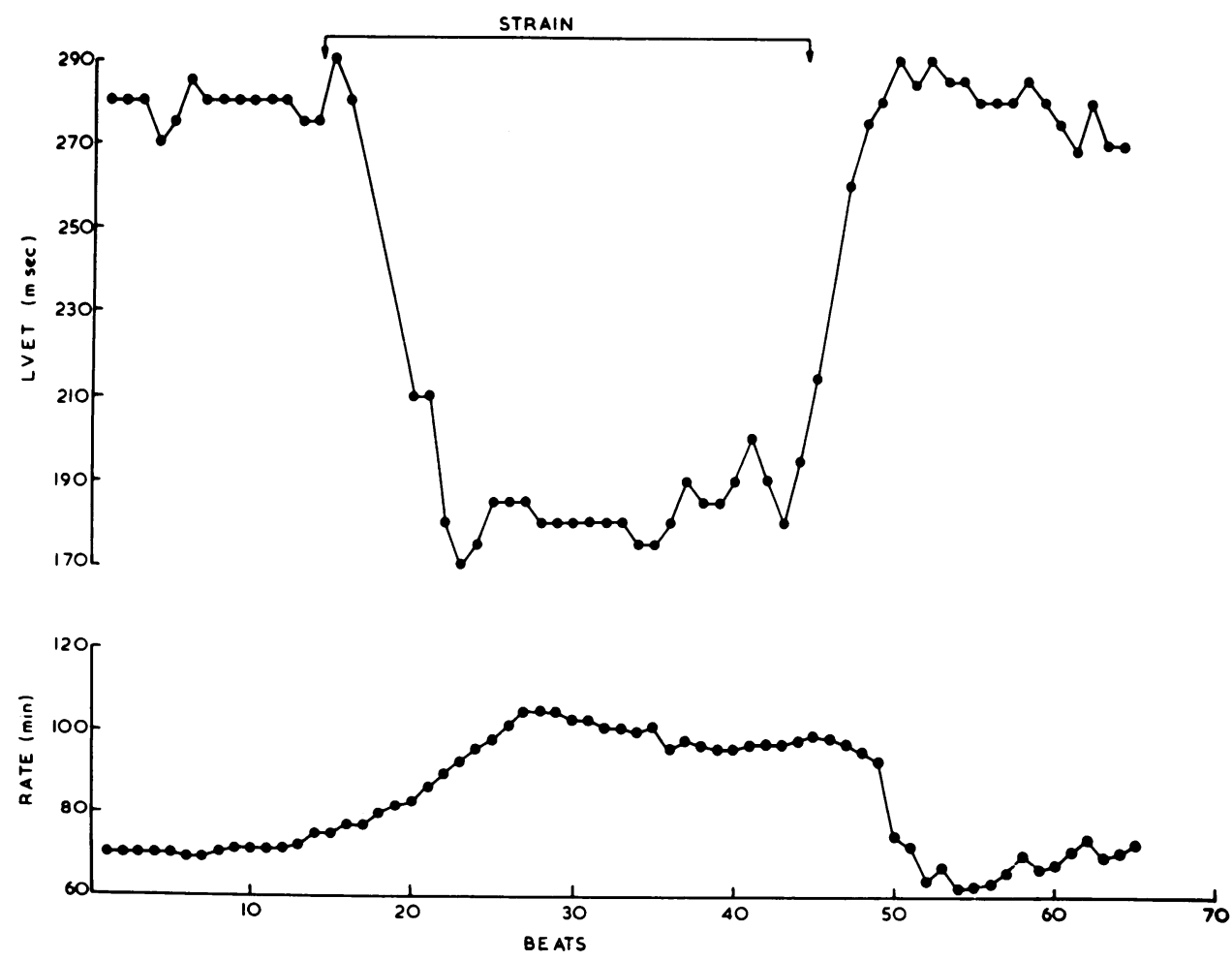

FIG. 4 Response of the heart rate and LVET during the Valsalva manoeuvre on a beat-bybeat analysis. Phase I, beginning at the onset of the strain, is followed by phase II in the steady state of straining. Phase III starts with the release of the strain and phase IV represents the recovery period. 


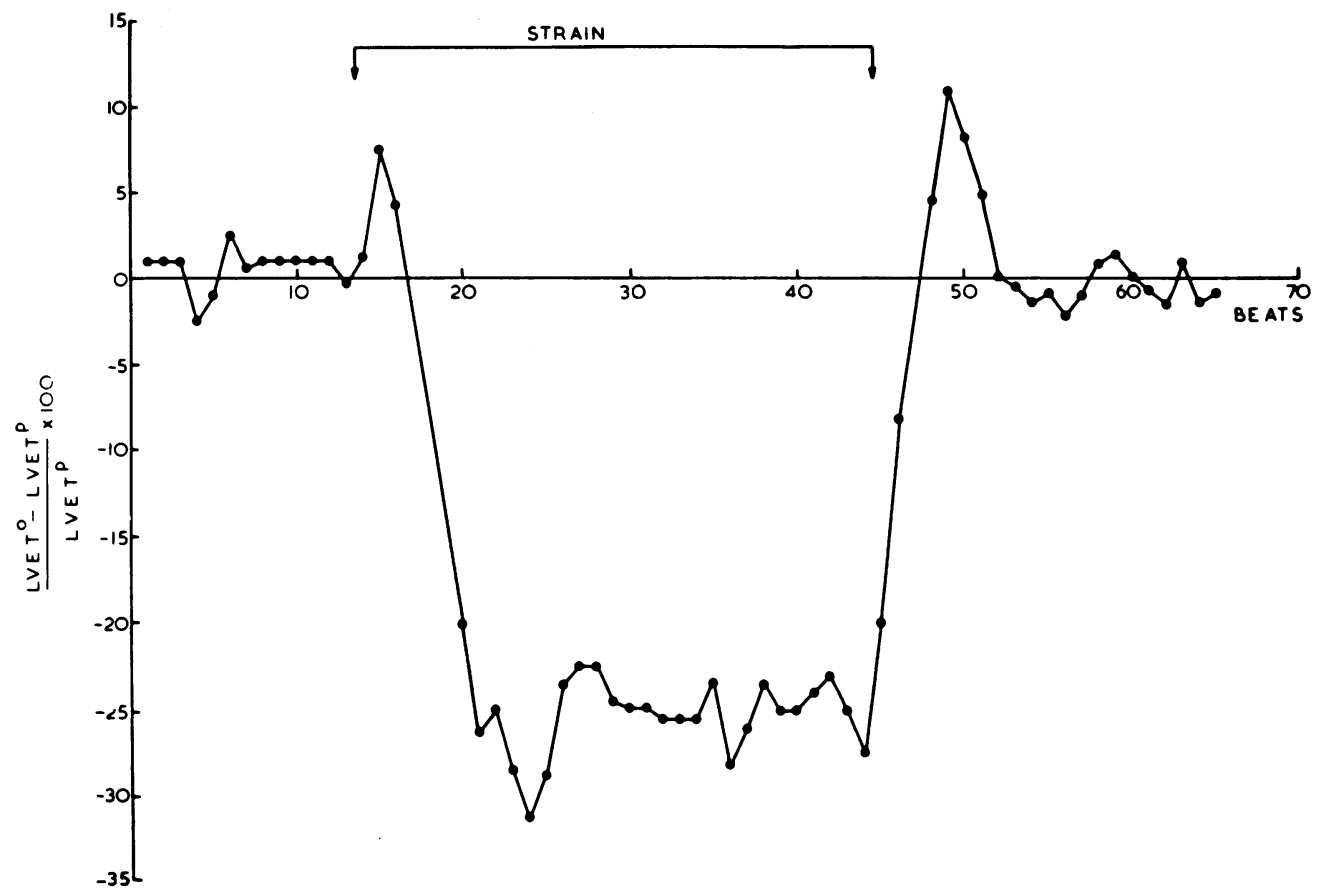

FIG. 5 Changes in the rate-corrected LVET ratio during the Valsalva manoeuvre on a beatby-beat analysis.

found for the normal subjects. After the 48-hour period of treatment with propranolol the resting LVET was increased in each case by 25 to 45 milliseconds. A fall in the heart rate was also seen, but

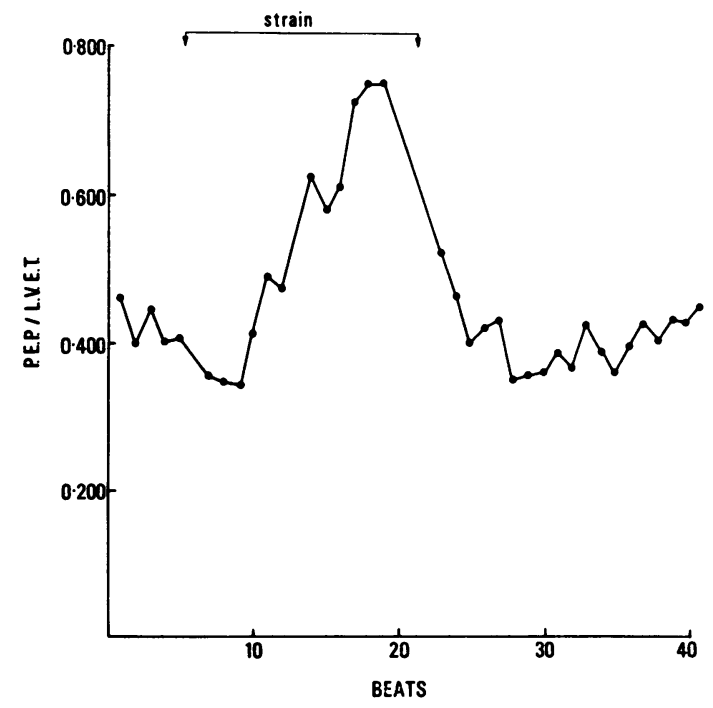

FIG. 6 Changes in PEP/LVET during the Valsalva manoeuvre on a beat-by-beat analysis. despite this there was an increase of 4 to 7 per cent in the rate-corrected LVET ratio. The response to the Valsalva manoeuvre during the strain period was unchanged, but after release of the strain no overshoot occurred (Fig. 7). In no case was any clinical or radiological evidence of left ventricular dysfunction observed during the period of treatment with propranolol.

In 3 of the 5 patients with primary myocardial disease no change was observed in the LVET, the rate-corrected LVET ratio, or the PEP during or after the Valsalva manoeuvre. The resting levels of the LVET were all below the normal range. In the remaining 2 patients the LVET remained constant until late in the strain period when an insignificant fall was recorded. This was also seen in the rate corrected LVET ratio (Fig. 8). After release of the strain the corrected LVET ratio returned to the control levels but no overshoot occurred in the first three cases, and only a small, insignificant overshoot in the other 2 (Fig. 8). The PEP remained constant throughout the Valsalva manoeuvre. As a result no significant change was observed in the PEP/LVET.

\section{Discussion}

The Valsalva manoeuvre is widely accepted as a reliable stress test providing information on the 


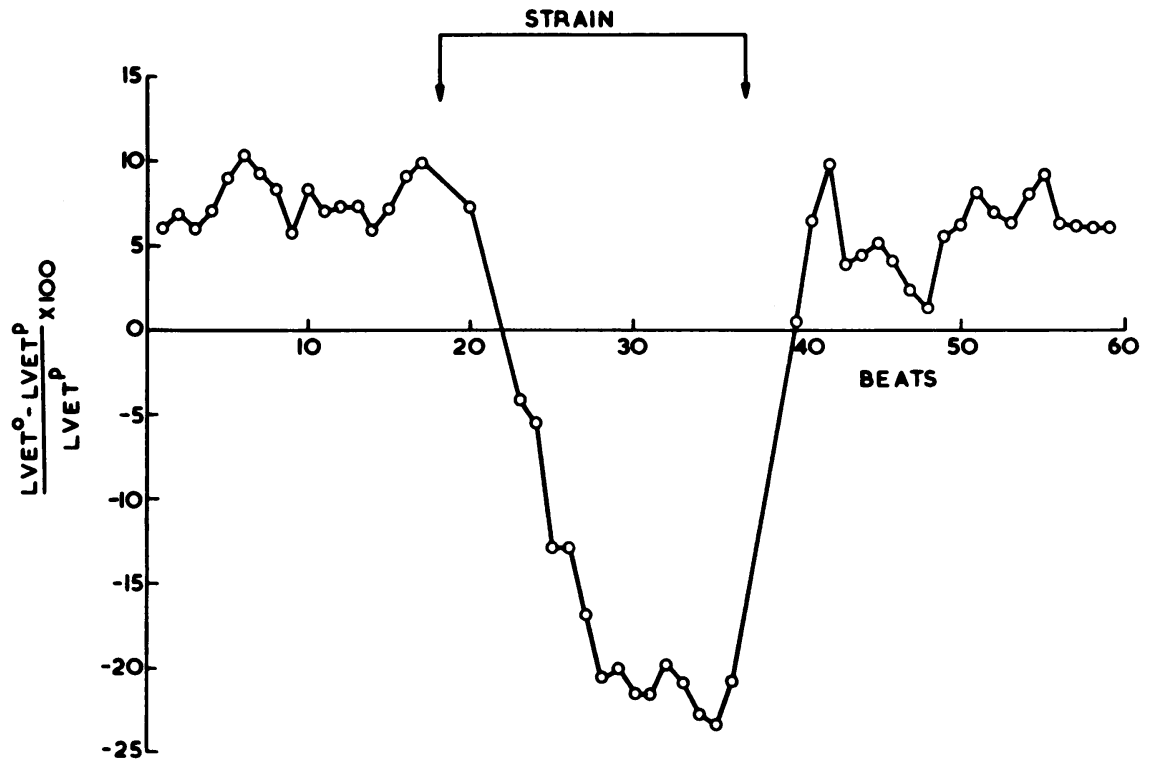

FIG. 7 Changes in the rate-corrected LVET ratio during the Valsalva manoeuvre after propranolol.

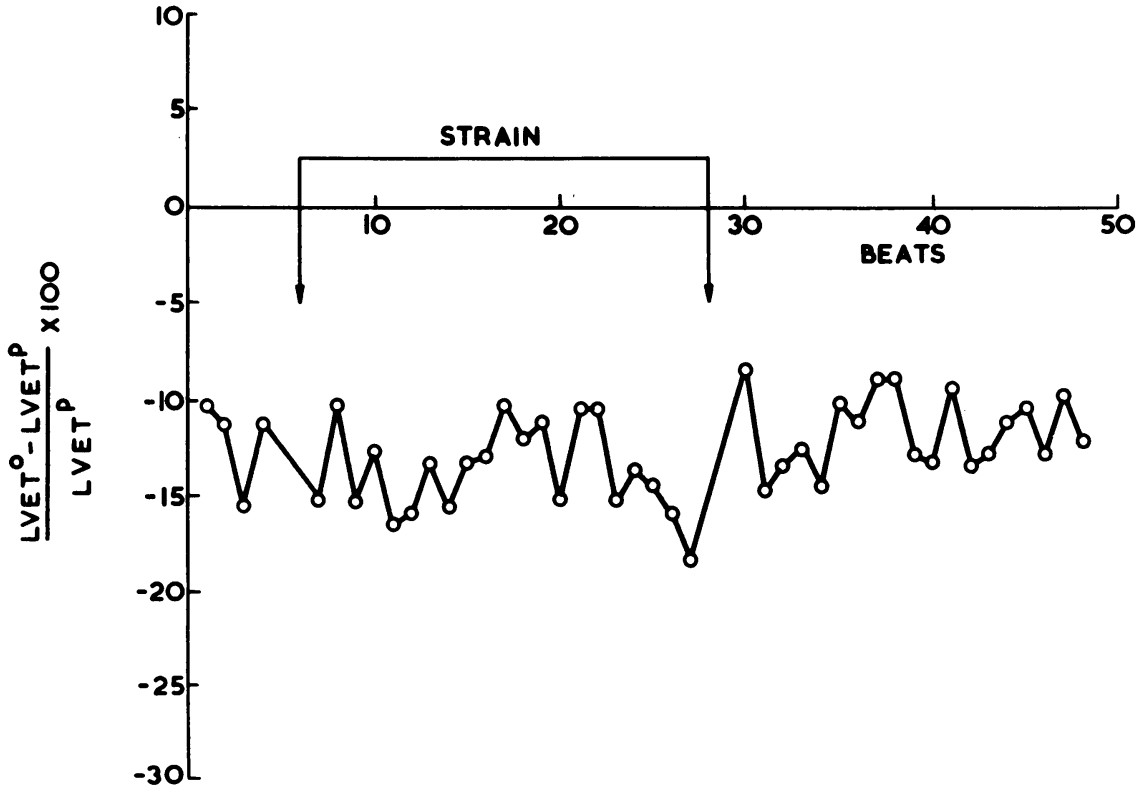

FIG. 8 The rate-corrected LVET ratio during the Valsalva manoeuvre in a patient with cardiomyopathy. 
function of both the cardiovascular and autonomic nervous systems (Gorlin et al., 1957; Elisberg et al., 1953). The response of the heart rate (Elisberg, I963) and systemic arterial pressure (Sarnoff et al., I948) during the Valsalva manoeuvre in normal subjects and in the presence of a variety of cardiac and autonomic disorders is known and the underlying mechanisms responsible for these changes established. While a partial assessment of the response to the Valsalva manoeuvre may be obtained from an analysis of the heart rate changes alone, it has been possible to make a detailed analysis of the response only if the systemic arterial pressure has also been recorded. The application of noninvasive methods to the assessment of the Valsalva manoeuvre offers many advantages, particularly in the ability to perform serial studies.

During the Valsalva manoeuvre, major alterations are observed in the heart rate, stroke volume, and peripheral vascular resistance. At the beginning of phase $I$ there is a rise in arterial pressure which is responsible for a decrease in the heart rate mediated through the baroreceptor system and the vagus nerve. Subsequently there is a progressive fall in the stroke volume and arterial pressure which results both in acceleration of the heart rate and an increase in the peripheral resistance. At the end of phase III a normal or increased stroke volume is ejected into a constricted peripheral vascular bed causing a sudden increase in both the systolic and pulse pressures and a reflex fall in the heart rate again mediated through the parasympathetic nervous system. Since these changes in the heart rate will, in themselves, affect the systolic time intervals, the changes in the LVET occurring as a result of the alteration in stroke volume may be masked by the rate-related factor.

In order to exclude this possibility the concept of a rate-independent LVET ratio was devised. Though regression equations relating the heart rate to the LVET are available, these have been derived by taking observations at a single heart rate in each of a group of normal subjects (Weissler, Peeler, and Roehll, I96I ; Flessas, Kumar, and Spodick, 1970). This may introduce a number of errors particularly with respect to the effect of other variables such as stroke volume. The method adopted in this study allowed estimation of the LVET to be made at a variety of heart rates in each normal person.

The haemodynamic effects after the infusion of atropine are dependent both on the dose administered and the time after administration at which measurements are taken. During the period in which the heart rate is increasing the haemodynamic changes induced by atropine are shown not to be significantly different from those observed at similar heart rates during atrial pacing (Kosowsky et al., 1966). Using either method for the induction of the tachycardia, there is a linear increase in the cardiac output but no change in the stroke volume (Kosowsky et al., 1966; Weissler, Leonard, and Warren, 1957). During the period after atropine infusion, in which the heart rate change has reached a plateau, there is a progressive fall in the stroke volume and the cardiac output associated with a fall in the ventricular filling pressure (Berry et al., 1959; McMichael and Sharpey-Schafer, 1944). The method of administration and dosage of atropine used in this study were such that the plateau of the heart rate was not reached and changes in the stroke volume minimized.

Using this technique, the linear relation between the LVET and the heart rate has been confirmed but the regression equation derived from the pooled data of the group of normal subjects shows that the LVET is less dependent on the heart rate than has been suggested from previously published data (Weissler et al., 1968; Morbelli, Mascaretti, and Giura, 1965). The finding of a lesser degree of dependence is consistent with the suggestion that the LVET at higher heart rates in previous studies was being depressed by a reduced stroke volume, thereby accentuating the apparent effect of the heart rate.

The changes in the LVET during the Valsalva manoeuvre in normal subjects closely followed the pattern described by Flessas et al. (1970) and the lack of change in the PEP is confirmed. As a result of this finding there is a conspicuous increase in the PEP/LVET at the end of the strain period. The levels achieved far exceed the accepted limits of normal and are higher than those observed in many patients with cardiac failure (Garrard et al., I970).

After elimination of the effects of the heart rate on the LVET, a clear pattern emerged which was reproduced in each normal subject. Immediately on start of the strain there was a rise in the corrected LVET ratio which is probably related to the increased intrathoracic and arterial pressures. Throughout phase II, the fall in stroke volume is reflected by a decrease in the corrected LVET ratio with a tendency for this fall to level off in the later stages. In phase III the increase in the stroke volume causes a conspicuous increase in the corrected LVET ratio which then returns to the control levels, but with a prominent respiratory variation.

It is of particular interest to note that the overshoot in the rate corrected LVET ratio after the strain period is not apparent in the uncorrected LVET. As might be expected, the changes which occur in the rate-corrected LVET ratio during the 
Valsalva manoeuvre bear some resemblance to the alterations in arterial pressure that are usually observed.

The failure of the LVET to fall in the 5 patients with cardiomyopathy suggests that the stroke volume was maintained at the control levels during the strain period and is compatible with an increased pulmonary blood volume maintaining left ventricular filling. This is analogous to the square wave response of the systemic arterial pressure during the strain period. In view of these findings, it is expected that no change will occur in the heart rate or the peripheral resistance and the post-release overshoot of the corrected LVET ratio is therefore not seen. Paradoxically, because there is no change in the LVET during the strain, the PEP/LVET remains constant and does not reach the high levels observed in the normal subjects.

The substitution of the pooled regression equation for the application of the rate correction in this group is justified, as the response of the LVET to changes in the heart rate in patients with myocardial dysfunction follows the normal pattern though the LVET at any given heart rate will be lower than normal because of the reduced stroke volume. The slope of the regression equation for subjects with normal and impaired myocardial function is therefore the same (Weissler et al., 1968; C. A. Layton, G.M. Gent, and A.H. McDonald, unpublished data).

After beta adrenergic blockade in the patients with ischaemic heart disease, two distinct changes were noted in the response to the Valsalva manoeuvre. The resting LVET increased and since this was accompanied by a rise in the rate-corrected LVET ratio the change in the LVET cannot be explained on the basis of the reduction in the heart rate after the administration of propranolol. The prolongation of the corrected LVET ratio is unlikely to represent a disproportionate increase in the stroke volume over that expected for the fall in the heart rate, since propranolol is known to diminish the stroke volume and the cardiac output (Sowton and Hamer, 1966), but probably reflects a fall in the mean systolic ejection rate resulting from the impairment of left ventricular function induced by propranolol (Hamer and Sowton, 1966). The loss of the post-release overshoot of the corrected LVET ratio is also compatible with impairment of the cardiac component of the Valsalva response, and is comparable to the diminution in overshoot of the arterial pressure observed after beta-adrenergic receptor blockade (Prichard and Gillam, 1966).

On the basis of these observations it is felt that the measurement of the rate corrected LVET ratio may provide a useful atraumatic method for the assessment of the cardiovascular and autonomic responses to the Valsalva manoeuvre which are of particular interest in view of the increasing use of autonomic blocking drugs in the treatment of patients with heart disease. The noninvasive nature of the investigation ensures a high degree of patient co-operation in the performance of serial studies.

We wish to thank Dr. Wallace Brigden and Dr. Lawson McDonald for their advice and encouragement, Mr. William Dicks for technical assistance, and our colleagues and the patients who acted as subjects.

\section{References}

Berry, J. N., Thompson, H. K., Miller, D. E., and McIntosh, H. D. (1959). Changes in cardiac output, stroke volume and central venous pressure induced by atropine in man. American Heart fournal, 58, 204.

Bowen, W. P. (1904). Changes in heart-rate, blood-pressure, and duration of systole, resulting from bicycling. American fournal of Physiology, 11, 59.

Elisberg, E. I. (1963). Heart rate response to the Valsalva maneuver as a test of circulatory integrity. Fournal of the American Medical Association, 186, 200.

Elisberg, E. I., Miller, G., Weinberg, S. L., and Katz, L. N. (1953). The effect of the Valsalva maneuver on the circulation. The role of the autonomic nervous system in the production of the overshoot. American Heart fournal, 45, 227.

Flessas, A. P., Kumar, S., and Spodick, D. H. (1970). Effects of the Valsalva maneuver on the cardiac systolic intervals: beat-to-beat versus timed analysis. American Heart fournal, 80, 522.

Garrard, C. L., Weissler, A. M., and Dodge, H. T. (1970). The relationship of alterations in systolic time intervals to ejection fraction in patients with cardiac disease. Circulation, 42, 455 .

Gorlin, R., Knowles, J. H., and Storey, C. F. (1957). The Valsalva maneuver as a test of cardiac function. American fournal of Medicine, 22, 197.

Hamer, J., and Sowton, E. (1966). Effects of propranolol on exercise tolerance in angina pectoris. American fournal of Cardiology, 18, 354.

Kosowsky, B. D., Stein, E., Lau, S. H., Lister, J. W., Haft, J. I., and Damato, A. N. (I966). A comparison of the hemodynamic effects of tachycardia produced by atrial pacing and atropine. American Heart fournal, 72, 594.

McMichael, J., and Sharpey-Schafer, E. P. (I944). Cardiac output in man by a direct Fick method; effects of posture, venous pressure change, atropine, and adrenaline. British Heart fournal, 6, 33.

Morbelli, E., Mascaretti, L., and Giura, R. (1965). I fattori che regolano la durata della eieizione ventricolare nell' uomo. Folia Cardiologia, 24, 124.

Pigott, V. M., Spodick, D. H., Rectra, E. H., and Khan, A. H. (1971). Cardiocirculatory responses to exercise: physiologic study by non-invasive techniques. American Heart fournal, 82, 632.

Prichard, B. N. C., and Gillam, P. M. S. (1966). Propranolol in hypertension. American fournal of Cardiology, 18, 387.

Sarnoff, S. J., Hardenbergh, E., and Whittenberger, J. L. (1948). Mechanism of the arterial pressure response to the Valsalva test: the basis for its use as an indicator of the intactness of the sympathetic outflow. American fournal of Physiology, 154, 316.

Shapiro,W., Narahara, K., and Taubert,K. (1970). Relationship of plasma digitoxin and digoxin to cardiac response following intravenous digitalization in man. Circulation, 42, 1065. 
244 Layton, di Nunzio, Gent, Freedman, and McDonald

Sowton, E., and Hamer, J. (1966). Haemodynamic changes after beta adrenergic blockade. American fournal of Cardiology, 18, 317.

Weissler, A. M., Harris, W. S., and Schoenfeld, L. D. (1968). Systolic time intervals in heart failure in man. Circulation, 37, 149.

Weissler, A. M., Leonard, J. J., and Warren, J. V. (1957). Effects of posture and atropine on the cardiac output. fournal of Clinical Investigation, 36, 1656.
Weissler, A. M., Peeler, R. G., and Roehll, W. H., Jr. (I96I). Relationships between left ventricular ejection time, stroke volume, and heart rate in normal individuals and patients with cardiovascular disease. American Heart fournal, 62, 367.

Requests for reprints to Dr. Clive A. Layton, Cardiac Department, The London Hospital, Whitechapel, London EI IBB. 